measuring about $3 \mathrm{~m} \times 3 \mathrm{~m}$ and three computers, which have only recently been connected to the internet. Psychiatric training of registered nurses is conducted by the Kenya Medical Training College but registration for this course is currently below the stipulated quota. Several public and private universities and colleges offer training in counselling psychology.

Finally, it has been suggested that traditional and faith healers play a significant role in mental health (Ndetei et al, 2007). Working with them and improving their skills through simple diagnostic training without seeming too keen to understand their trade (which they guard) may win their confidence and improve collaboration and referrals to the formal mental health services.

\section{Research, policy and advocacy}

There is still a lot that is not known about the prevalence rates of the whole spectrum of mental health problems across the continuum of life, in different situations and environments, for example poverty and mental illness, and how these complement each other. Other areas not yet adequately researched are the people who come into contact with the law, particularly prison populations, orphans, and community mental health and well-being. Research on the provision of good, affordable, accessible and appropriate services in particular socio-cultural and economic contexts should also be conducted. Research on simple issues of concern such as the regional distribution of psychiatrists within the country over time has led to the stark realisation that, rather than waiting until there are enough psychiatrists, radical policy strategies on how best to meet the service and training needs of Kenya have to be devised. Although some progress has been made through research in schools on issues such as substance use and misuse, psycho-trauma and anxiety and depressive disorders, there is still much that needs to be done.

Research is necessary not only for good practice but also for appropriate, evidence-based policies that are costeffective. The final policy makers (the politicians) will listen to technocrats only if the latter are armed with locally generated evidence that relates to the mental health of the electorate (which is what the politicians value most).

In Kenya today, a lot of mental health research is done through masters and doctoral theses, mainly in the Department of Psychiatry at the University of Nairobi and a few departments in other universities which offer health-related courses. The remaining (non-dissertation) mental health research is done mainly by a few individuals and nongovernmental organisations (NGOs). Notable among the NGOs is BasicNeeds UK (Kenya), which spearheads research in mental health in relation to poverty. Through this programme, a community research laboratory in an urban area has now been put in place and a rural one is being considered. It will be possible to conduct epidemiological research on community mental health and well-being across the continuum of life, as well as to carry out intervention studies through these laboratories; in due course these studies can be replicated in other parts of the country.

At present, most of the research related to mental health is being undertaken by the Africa Mental Health Foundation (AMHF), which brings together interested researchers from different backgrounds and different universities within and outside Kenya. The AMHF fosters collaborative research and supports research by BasicNeeds UK (Kenya) and other international collaborators. It also supports annual award schemes for outstanding students in mental health/psychiatry (both clinical and research) at the University of Nairobi and the best nurse in mental health.

Perhaps the most significant recent development is the formation of the University of Nairobi's Medical Students Association for Research and Statistics. The Association has plans to extend to other medical schools within the region and also to foster collaboration with similar organisations world-wide. Its patron is the author, and one of the main objectives is to sensitise students to the importance of research during their formative years.

\section{Reference}

Ndetei, D. M., Ongecha, F. A., Mutiso, V., et al (2007) The challenges of human resources in mental health in Kenya. South African Psychiatry Review, 10, 33-36.

\title{
Provision of mental health services in Nigeria
}

\section{Olufemi Olugbile, M. P. Zachariah, O. Coker, O. Kuyinu and B. Isichei}

Lagos State University Teaching Hospital, Ikeja, Lagos State, Nigeria, email femi_olugbile@yahoo.com

$\mathrm{N}$ igeria, like other African countries, is short of personnel trained in mental healthcare. Efforts to tackle the problem have often focused on increasing the numbers of psychiatrists and nurses in the field. These efforts, over the past 20 years, have not appeared to have greatly improved service delivery at the grass roots. Most of the specialist centres where such highly trained personnel work are in urban areas and for a large part of the population access to them is limited by distance and cost.

Mental healthcare is one of the recognised elements of primary healthcare in Nigeria. Primary health centres (PHCs) are supposed to have a reasonable amount of competence in recognising and dealing with some of the more common mental disorders. They are the first point of contact for many 
individuals and serve as the first link in the referral system. The population ratio of psychiatrists is $0.4: 100000$, while for psychiatric nurses it is 4:100000 (World Health Organization, 2001).

In this paper we describe two audits in Lagos State undertaken (as part of a larger survey of core personnel and facilities available for psychiatric services) to evaluate the use of non-specialist resources, specifically PHCs and general practitioners (GPs), potentially available for the provision of mental healthcare, and examine their present state of functioning and participation in it. Insights are derived about how they could be harnessed to provide more effective coverage for mental healthcare.

\section{Methods}

The audit of PHCs focused on available personnel and physical resources (drugs and equipment) relevant to the care of people with mental illness. An evaluation of the knowledge base and attitudes of the identified personnel in these centres, as they pertain to mental illness, was conducted using specially designed questionnaires. These instruments were pre-tested in five pre-selected PHCs, and were found to be appropriate and adequate. Five of the 20 local government areas of the state were randomly selected. Within each area, three PHCs were randomly selected for assessment. Thus a total of 15 PHCs were included in the study. These centres together had a total of 73 personnel, who were all included in the survey.

The knowledge base and attitudes of GPs as well as appropriate physical resources (drugs and equipment) available in their respective clinics as they pertain to the treatment of mental illness were also audited, using another specially designed questionnaire. This instrument was pre-tested on 10 GPs and was similarly found to be adequate and appropriate.

Items in the questionnaires used for both the PHC and GP surveys were independently scored by two experts (both psychiatrists). Four core questions in the PHC instrument (Table 1) and three core questions in the GP study (Table 2) were rated by these two experts on a five-point scale ( 0 indicating no knowledge and 4 indicating very good knowledge). The mean of the scores assigned by the two experts for each response was given as the response score for each participant in the study. Composite scores for each participant were also computed to reflect overall knowledge and attitude. The expert inter-rater correlation (Pearson product-moment) was significant (for the PHC survey, $n=73$, correlation coefficient $=0.70, P<0.001)$.

\section{Results}

\section{Audit of PHCs}

A general finding was that none of the PHCs surveyed had any stock of psychotropic drugs in its pharmacy.

The 73 staff in the PHCs comprised the following professional categories:
O 21 nurses (29\% of the sample)
18 community health workers $(25 \%)$
15 community health extension workers (20\%)
o 8 administrative officers (11\%)

Table 1 Knowledge and attitude ratings of the PHC personnel

$\begin{array}{llll}\text { Item } & \text { Mean } & \text { s.d. } & \text { Range } \\ \text { Knowledge of definition of mental disorder } & 1.41 & 0.65 & 0-3 \\ \text { Knowledge of categories of mental illnesses } & 1.32 & 0.76 & 0-3 \\ \text { Understanding of causation } & 1.57 & 0.63 & 0-3 \\ \text { Knowledge of treatment modalities } & 1.16 & 0.69 & 0-3 \\ \text { Overall rating } & 1.39 & 0.49 & 0-2.88\end{array}$

Expert ratings of knowledge and attitude, where $0=$ no knowledge and $4=$ very good knowledge. A generally poor level of knowledge regarding mental illness, its manifestations and management emerged across all categories.

Table 2 Knowledge and attitude ratings of the GPs

$\begin{array}{llll}\text { Item } & \text { Mean } & \text { s.d. } & \text { Range } \\ \text { Knowledge of basic classification } & 1.49 & 1.19 & 0-4 \\ \text { Diagnostic ability } & 1.39 & 0.95 & 0-3.5 \\ \text { Management } & 1.04 & 1.05 & 0-3 \\ \text { Overall rating } & 1.32 & 0.90 & 0-3.33\end{array}$

Expert ratings of knowledge and attitude, where $0=$ no knowledge and $4=$ very good knowledge. A generally poor level of knowledge across all levels emerged. Knowledge of basic classification was rated highest, while management knowledge was the poorest.

\section{6 pharmacy technicians (8\%)}

5 cleaners (7\%).

There were no doctors working in the PHCs at the time of the survey. The core clinical functions were carried out by nurses, community health workers and community health extension workers. These three categories also formed the bulk of the workforce. Pharmacy technicians provided technical support.

The expert ratings of the knowledge and attitudes of these staff are summarised in Table 1. More than half the personnel had had at least graduate-level education; three (4\%) were postgraduates. Most of the remaining staff had completed their secondary education, although five (7\%) had received only primary education.

\section{Audit of GPs}

General practitioners from all across Lagos State were surveyed. The venue of the survey was the meeting of the Association of General Medical Practitioners. Of the 51 surveyed, one failed to return the questionnaire. Fifty participants thus were included in the study.

Most of the GPs (44 out of 50) saw psychiatric patients in their practices, but this left a sizeable number (6) who did not see psychiatric patients at all. Moreover, only 30 (60\%) of the practitioners actually treated patients for psychiatric disorders; the remaining 20 (40\%) would not treat mental illness even if they recognised it. Such individuals were presumably referred to specialist facilities for management.

The expert ratings of the knowledge and attitudes of the GPs are summarised in Table 2.

\section{Psychotropic drug stocks}

Only $8(16 \%)$ of the GPs stocked a broad range of psychotropic drugs, and only 4 (8\%) stocked both antipsychotic and antidepressant medications. Twenty (40\%) had only antipsychotic drugs and 10 (20\%) had only antidepressant drugs, while $8(16 \%)$ did not stock any psychotropic medications at all. 


\section{Discussion}

The burden and pattern of psychiatric morbidity can be seen from available epidemiological data (Gureje et al, 1992; Abiodun, 1993). An idea of what is attainable within the primary health system can be seen from research done in other countries (Bilsker et al, 2007; Kates \& Mach, 2007; Paria \& Perez, 2007).

Nigeria is under-resourced in terms of psychiatric personnel and infrastructure. Access to care for the majority of people with mental illness is severely limited. Efforts to address this problem have so far been targeted at increasing the numbers of psychiatrists and psychiatric nurses, who are often located in urban specialist units.

The PHCs are the facilities closest to the majority of citizens. The research presented here shows that the knowledge base and interest of staff in the PHCs concerning mental illness are low. Further, unlike earlier reports on the matter (Gureje, 2005), it also shows that they do not have even the most basic drugs for treatment.

General practitioners have been a neglected force in mental healthcare planning in Nigeria. If the awareness, knowledge level and attitudes of GPs and PHC workers about mental health could be upgraded in a targeted way, it would lead to an increase in the numbers of people treated for their mental illnesses, especially those with 'minor' disorders. It could also create the beginning of a referral chain that would help to prevent the loss to clinical follow-up of individuals who have had specialised treatment in distant teaching hospitals or psychiatric hospital units.

\section{References}

Abiodun, O. A. (1993) A study of mental morbidity among primary care patients in Nigeria. Comprehensive Psychiatry, 34, 10-13.

Bilsker, D., Goldner, E. M. \& Jones, W. (2007) Health service patterns indicate potential benefit of supported self-management for depression in primary care. Canadian Journal of Psychiatry, 52, 86-95.

Gureje, O. (2005) Nigerian Mental Health Atlas 2005. WHO.

Gureje, O., Obikoya, B. \& Ikuesan, B. A. (1992) Prevalence of specific psychiatric disorders in an urban primary care setting. East African Medical Journal, 69, 282-287.

Kates, N. \& Mach, M. (2007) Chronic disease management for depression in primary care: a summary of the current literature and implications for practice. Canadian Journal of Psychiatry, 52, 77-85.

Paria, B. \& Perez, C. (2007) Schizophrenic disorder in primary care mental health. Aten Primaria, 39, 119-124.

World Health Organization (2001) Atlas: Country Profile of Mental Health Resources. WHO.

\section{Psychiatry in Brunei Darussalam}

\section{Reehan Sabri' ${ }^{1}$ and Ajmal-Khan Kudlebbai} ${ }^{1}$ Consultant Psychiatrist, Mental Health Unit, RIPAS Hospital, Bandar Seri Begawan, Brunei Darussalam BA 1710
email reehansabri@hotmail.com ${ }^{2}$ Staff Grade Forensic Psychiatrist, Three Bridges Regional Secure Unit, West London Mental Health NHS Trust, London, UK

$B^{n}$ runei Darussalam occupies a sliver of land on the northwest coast of the island of Borneo with a geographical area of just $5765 \mathrm{~km}^{2}$ (Government of Brunei, 2004). It is divided into the four districts: Brunei-Muara, Temburong, Tutong and Belait. Two-thirds of the land is covered by lush tropical rainforest and the climate is perpetually warm and humid. It is ruled by Sultan Hassan Al-Bolkiah, the head of a dynasty which has governed Brunei for 650 years.

The population of 374000 (United Nations Population Fund, 2005) enjoys one of the highest standards of living anywhere in the world, thanks to the discovery of oil in 1929, but the economy remains almost entirely dependent on oil and gas. The Bruneian population is $66 \%$ ethnic Malay and $15 \%$ ethnic Chinese; the rest are a mixture of indigenous and other races, such as the Ibans, who were once the feared headhunters of Borneo. There is also a large population of expatriate workers from the Indian subcontinent, South-East Asia, Australasia and Europe.

\section{Religion and culture}

The different cultural groups in Brunei have interesting beliefs about physical and mental health (Kumaraswamy, 2007). These often present a challenge to medical practitioners and psychiatrists in particular. In spite of the official state adoption of Islam, many Malays adhere to beliefs that are a mixture of Islam, misunderstandings of Islam, animism and Hinduism, and this religious stance is a major influence on their beliefs about health. The Chinese and indigenous communities also have their superstitions and forms of traditional medicine.

Unsurprisingly, therefore, the first line of help for any kind of ailment among Bruneians, particularly psychiatric, is the Malay shaman or Bomoh. Bomohs practise a type of folk medicine under the veneer of Islam but their heretical practices are frowned upon by the religious authorities. Their knowledge is passed from generation to generation (Abdul 